\title{
Ethical aspects of workplace urine screening for drug abuse
}

\author{
Alexander R W Forrest Royal Hallamshire Hospital, Sheffield
}

\begin{abstract}
Objective - To review the ethical and legal implications of the involvement of medical practitioners in workplace screening for drug misuse.

Conclusions - Workplace screening for drugs of abuse raises many ethical issues. If screening is considered as being part of medical practice with the involvement of occupational health physicians, as suggested by the Faculty of Occupational Medicine, then the ethical requirements of a normal medical consultation are fully applicable. The employee's full and informed consent to the process must be obtained and the employee should have an unfettered right of access to all the relevant records and to the urine sample he/she has provided in the event that he/she wishes to challenge the opinion expressed by the physician. If the process is not part of medical practice then employees should have the same rights as they would have if required to provide intimate body samples in the course of a criminal investigation, given the potentially serious consequences of an erroneous positive finding for their livelihood.
\end{abstract}

\section{Introduction}

There can be little doubt that regular urine screening for the presence of misused drugs in urine has a salutary sentinel effect and, in time, reduces the proportion of positive tests in the population under scrutiny. ${ }^{1}$ There is surprisingly little evidence that the testing of employees for evidence of drug misuse by urine analyses has any significant effect on accident rates. ${ }^{2}$ Despite this the enactment of the Transport and Works Act 1992 into law has resulted in most operators of passenger transport systems in the UK introducing some form of urine drug screening for their operational staff. Other industries, such as the nuclear industry, the oil industry and companies doing work for the US federal government also have policies in place for employee urine drug screening. ${ }^{3}$ I wish to argue that the way in which employee urine drug screening is carried out in the

\section{Key words}

Workplace drug screening; access to samples; ownership of samples; ethical obligations of medical review officers.
United Kingdom is often unlawful, does not adequately protect the rights of the employee and can create very serious ethical difficulties for the health $\underset{\omega}{ }$ care professionals involved in the process.

\section{Urine drug screening}

The Faculty of Occupational Medicine of the Royal T College of Physicians has recommended that workplace drug screening should be done under the direction of occupational health physicians. ${ }^{4}$ Under ${ }^{2}$ such circumstances the process is clearly a medical $\vec{\emptyset}$ one involving a definite doctor-patient relationship.

The first step in the process is the collection of the urine sample. Employees may be informed that failure to attend to provide a sample on a particular day will be regarded as the equivalent of the provision of a positive sample. In many cases the nonprovision of a sample could lead to dismissal and would certainly lead to the exclusion of a candidate for employment when drug screening is done as part of a pre-employment medical examination. The collection process is normally supervised by a nurse or a specially trained "collection officer". This will $\bar{\varnothing}$ inevitably result in a loss of privacy for the individual $\stackrel{\square}{\circ}$ providing the urine sample. Before providing the sample the subject will normally be asked to complete a form in which she lists all the medication she is currently or has recently been taking and in which she consents to the analysis of the sample and the disclosure of the results to either a clinician or to an authorised person in the organisation requesting the analyses. The identification of the person provid-c ing the urine sample has to be verified, the sample 0 has to be voided with a degree of supervision that $\mathbb{\omega}^{N}$ obviates sample adulteration or substitution by the employee, or anyone else, and then placed in tamper-evident containers for transmission to the $\frac{C}{\Phi}$ testing laboratory. Usually the urine provided is $\stackrel{?}{+}$ divided into two aliquots, both of which are sent to 7 the laboratory. Only one of the aliquots will be웅 analysed in the first instance, with the second being stored in case of a later challenge.

At the laboratory, after verification that the tamper-evident seals on the containers are intact, the urine is first analysed by an immunochemical 
screening method. Positive results are then confirmed by a more specific technique based on different analytical principles, namely gas chromatography - mass spectrometry. If a positive analytical result is confirmed then, before the results are passed to management or to the occupational medical department, they are scrutinised by a "medical review officer" who determines whether or not the analytical results indicate drug abuse. Throughout the process a meticulous audit trail has to be maintained to ensure that the results obtained can be attributed with total confidence to the urine sample supplied by the particular employee and that there is no possibility of interference with the urine sample during the pre-analytical or analytical stages of the process.

If the medical review officer's opinion is that the analytical results do indicate drug abuse, then disciplinary action usually resulting in the termination of employment may result, although some employers do have in place carefully written substance abuse policies. In such cases the employee providing a sample yielding a positive result may be offered counselling, with dismissal only following if attempts at rehabilitation fail. However, dismissal following the first provision of a positive urine drug test backed up by a medical review officer's opinion that this indicates substance abuse does occur. In some companies, despite the recommendations of the Faculty of Occupational Medicine, the results are passed not to the occupational health department but to the personnel department.

\section{The employer's reasons for screening employees for drug misuse}

Transport system workers in certain safety-critical categories commit an offence if they are unfit for work through drink or drugs. ${ }^{5}$ These categories include drivers, guards, conductors, signalmen, others who can control or affect vehicle movement, maintenance workers and their supervisors and lookouts. The operators (management) of the transport system also commit an offence if one of their workers in a safety-critical capacity is unfit for duty through drink or drugs. However, management have a statutory defence if they have exerted "all due diligence" to prevent one of their workers being unfit for duty through drink or drugs. ${ }^{6}$ Thus transport system managers have good statutory reasons to put in place policies for detecting and deterring drug misuse in their employees.

The requirement of the Health and Safety at Work etc Act 1974 to provide a safe system of working for employees and to take into account those who might be put at risk by acts of omission by employees may also persuade companies to implement a drug screening policy. ${ }^{7}$ There is limited evidence that, in the context of employment in the UK, the implementation of such a policy would bring any objective benefits in terms of a reduction in accidents at work. Obviously the exclusion of the intoxicated or drug-impaired worker from the workplace is very highly desirable. The benefits of excluding the worker who engages in the occasional use of intoxicants outwith working hours and who has a satisfactory working and sickness record are less apparent. Thus a major reason for the introduction of such policies by UK-based companies, outwith the transport sector, must be as a pre-emptive public relations measure intended to mitigate the adverse publicity that would result from the low-probability event of an accident involving an allegedly drug or alcohol-impaired employee. Under such circumstances, where there is no overriding public interest, the rights of the employee who is subject to such testing are paramount.

\section{Who owns the sample?}

One of the rights of employees that is often compromised by employers is that of access to their urine sample when a positive result is obtained that they wish to challenge. The usual practice at the time of urine sampling is to divide the sample into two parts, sealing both into tamper-evident containers. The employer retains both urine samples and both are usually submitted to the laboratory, although only one sample is analysed, the other being kept intact in case of a challenge. This practice can be contrasted with the statutory procedure for the collection of blood or urine samples from a driver who is suspected of being unfit to drive. Here the results of any analyses cannot be used by the prosecution unless the specimen provided by the driver is divided into two and the second part has been "supplied to the accused". ${ }^{8}$ When the employee wishes to challenge the analytical results obtained then it is apparently the policy of many employers not to release the sample to the employee but to impose conditions, such as insisting that the second sample is analysed by an analyst approved by the employer or even that the urine samples are not released at all but are reanalysed at the laboratory that carried out the first analyses, in the presence of a representative of the employee approved by the employers. In short, the employers act as if they have an unfettered right of ownership of the urine samples provided by their employee. I suggest that they do not have such a right of ownership and such practices are thus unlawful.

Whilst a dead body is not property, ${ }^{9}$ there is little doubt that parts of a body can become property. For example, the Court of Appeal has considered cases where it has decided that specimens of blood or urine are property in that they can be stolen. ${ }^{1011}$ Human hair is an object of commerce as is blood and components of blood for transfusion. Erythopoetin, and other substances of therapeutic value, have been isolated from urine obtained and processed on a 
commercial basis. If rights of property can exist in samples of urine then those rights can be transferred. The issue is clearly whether or not the consent of the employee to supply a sample of urine for testing constitutes the transfer of all property rights in the sample to the employer. I suggest that, in the absence of a specific agreement by the employee to abandon all rights of property in the samples, it does not. Brahams has suggested that the donation of clinical samples may constitute a gratuitous bailment. ${ }^{12}$ A gratuitous bailment is created "whereby there is a delivery of good or chattels to somebody, who is to carry them or do something with them gratis, without any reward for such his work or his carriage". ${ }^{13}$ This concept would seem to be entirely applicable to the circumstances under which the employee gives a sample of his urine to the employer. The urine is given without any payment for the employer to test for the presence of drugs of abuse. If the terms of the agreement are breached then the employee has a right to immediate possession of the sample. If the employee considers that the results of the analysis are, or may be, wrong, that is that the analysis has not been done in a satisfactory manner, then the right of possession of the samples reverts to him. The employer might be able to challenge this, by arguing that the analysis was done in a satisfactory manner, but this would be a matter for the court. Thus, when the employee requests the return of the sample for his own analysis, because he considers that the terms of the bailment have been broken by the employer executing the analysis in an unsatisfactory manner, the employer either has to hand over the samples without conditions or to prove in court that the analysis was satisfactory. For the employer to refuse to return the samples to the employee or attempt to impose conditions on their return may well be unlawful and is certainly subject to challenge in the courts.

\section{Reduced rights}

A simple expedient which an employer might adopt to avoid this situation would be to include in the consent form completed by the employee before the urine sample is provided a clause in which the employee states that he abandons all rights of property in the sample and that the consequences of this have been explained to him and that he understands them. Such a clause would significantly reduce the rights of the employee who wished to challenge an analysis and should only be included by agreement with the relevant trades unions or employees' association. It would also imply that the provision of such a urine sample is something other than a normal part of a patient-doctor relationship.

The position of the employer is easy to understand; there are some "experts" whose expertise in the relevant areas is, at the least, questionable and who might be regarded as "liars for hire". Employers

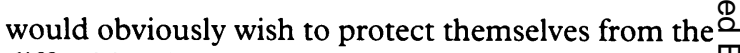
difficulties that a report produced by such an expert $\frac{\text { W }}{F}$ might create. It could be argued that employers are entitled to restrict access to a challenged urine sample to analysts approved by them by analogy with the concept of the "authorised analyst" definedo in legislation relating to road traffic offences. ${ }^{14}$ The $\bar{O}$ application of this argument would, of course, $\frac{\bar{\rho}}{\frac{1}{2}}$ obviate any suggestion that the process of workplace $\mathbb{Q}$ urine drug screening is a purely medical matter rather than an issue of policy or enforcement. In any case, the sole right of the authorised analyst as? defined in the Road Traffic Act is to submit his $\overrightarrow{\vec{\omega}}$ report as a certificate of analysis rather than as a statement. There is no reason why, in a road traffic $\overline{\bar{B}}$ case, the defendant should not choose to have his portion of the specimen he provided analysed by $\omega$ someone other than an authorised analyst. The $\vec{\overrightarrow{ }}$ analyst thus chosen could prepare his report in the $\vec{N}$ form of a statement. If the prosecution did not then 음 accept that statement then the analyst could be called to court to give his evidence in person, and be $\mathbb{T}$ subject to cross examination.

\section{The role of the health professional in workplace drug screening}

When medical practitioners become involved in the process of workplace drug screening then the employee will have a right of access to the records of the analyses done on his urine sample for it would be difficult to argue that the analyses were not carried $\stackrel{\varnothing}{\varnothing}$ out in connection with the medical care of the $\stackrel{\Rightarrow}{\Rightarrow}$ employee in the context of occupational health. ${ }^{15}$ In $\frac{\text { O }}{3}$ addition, if the report of the analysis is to be considered to be a medical report, and the involvement of a medical review officer implies that it should be, then the employee has a clear legal right of access to the report before it is passed to management and on $\dot{\sigma}$ gaining such access has a clear legal right to request either that the report not be supplied to management $\delta$ or to request that the medical practitioner involved amend the report if she considers it to be incorrect or $\frac{9}{7}$ misleading. If the medical practitioner is unwilling to $D$ amend the report then she must, if requested, attach a statement outlining the employee's views on the relevant part of the report. ${ }^{16}$ Similarly, the principle of freedom of choice in medical care would imply $\tilde{N}$ that it is unethical to restrict access by the patient to his urine sample simply as a matter of policy. If the employee is a patient of the occupational healtho physician when he supplies a urine sample for drug $\overparen{D}$ testing then the normal obligations and duties of the $\stackrel{?}{+}$ doctor-patient relationship exist, including the right $T$ of the patient to seek a further opinion, in this case a $\frac{\vec{P}}{\Phi}$ re-analysis of his sample by an analyst of his choice. $\stackrel{\mathbb{\Omega}}{\Omega}$ Whilst not specifically referring to occupational $\stackrel{\mathbb{Q}}{\varrho}$ health physicians, the General Medical Council $\bar{\sigma}$ enjoins doctors to respect the right of a patient to a second opinion. ${ }^{17}$ 
Thus, there appears to be little legal and no ethical justification for the policy adopted by some occupational health departments or personnel departments in restricting the access of employees to the urine samples they have provided when employees wish to have those samples re-analysed or when they wish to see the records of the analysis.

\section{Interpretation difficulties}

Once the urine analysis has been carried out on behalf of the employer the results are scrutinised by a medical review officer before they are released to the employer. The medical review officer's role is to determine whether or not a positive analytical finding indicates drug misuse and, if so, to produce a report which will be forwarded to management. The production of a positive report indicating drug abuse may well result in disciplinary action against the employee, with termination of employment being a common outcome. Determining whether or not a positive analytical result indicates drug misuse is not as straightforward as might appear. For example, morphine can be detected in urine not only after heroin use but also a day or two after taking over-thecounter medicines containing codeine or even after eating biscuits containing poppy seeds. ${ }^{18}$ Six-acetylmorphine, usually regarded as a specific marker of heroin use, is only present in urine for a day or less after heroin use and consequently its absence from urine may not exclude past heroin use. ${ }^{19}$ Clearly, the interpretation of a finding of morphine in urine requires a considerable degree of expertise. Similar difficulties exist in the interpretation of the presence of other commonly misused drugs and their metabolites The interpretation of a finding of cannabinoids in urine may be particularly difficult, even if passive smoking is not an issue. ${ }^{20}$ Cannabinoids may be found in urine for many days after the last use of cannabis. Consider the situation of a non-cannabis user who attends a party one Saturday night at which, unknown to her, comestibles containing cannabis are being served. Cannabis is being smoked at the party, but she does not accept any. She consumes a considerable amount of alcohol and what is apparently an ordinary sweetmeat. She attributes her pleasant intoxication to the alcohol she has consumed and thinks no more of it. The next Monday she goes into work as usual and is asked to provide a urine sample as part of a workplace drug screening programme as she has done on several previous occasions. Her supervisor has noticed no deterioration in her performance at work and the sample has been requested as a routine random check. She is horrified when she learns that her urine sample has been reported as containing cannabinoids. She is interviewed over the telephone by the medical review officer who then reports that the cannabinoids are present in her urine as a result of drug abuse. Consequently she loses her job.
There are many ethical issues inherent in the medical review officer's role. This is particularly the case where an occupational health physician with a fiduciary relationship with the employee also acts as the medical review officer. Obviously, the normal requirements of consent to examination and permission for the disclosure of the results of the examination have to be adhered to and the medical review officer cannot be exempt from the requirement to act in good faith in the best interests of the patient, even though she is paid by the employer or a third party in contract with the employer. The situation is analogous to that of the forensic medical examiner (police surgeon) whose obligation to carry out an examination and make a report to a police officer only with the consent of the detained person he has been asked to examine is well established. ${ }^{21}$ It is questionable whether informed consent could be given by an employee other than after a careful explanation in person of the aims and purposes of the consultation with the medical review officer and the consequences of declining to give such consent. If the medical review officer conducts his consultation and reports his conclusions without obtaining informed consent then he is open to both civil litigation and professional disciplinary proceedings.

\section{Training}

Clearly, if equitable results are to be achieved in a drug screening programme, then medical review officers must be well trained and competent. This implies a considerable degree of relevant postgraduate training. I am aware of one case where a person acted as a medical review officer approximately two years after full registration with the General Medical Council. I would suggest that it is inappropriate for anyone to undertake the considerable responsibilities of this role unless he or she has a sufficient level of training in a relevant specialty to be eligible for specialist registration with the General Medical Council. Also, I would suggest that the importance of the results of the medical review officer's opinion are so crucial for the employee that they should be based not only on the laboratory analyses but also on an appropriate clinical examination of the patient, not merely, as is a common practice, a telephone interview. The General Medical Council suggests that patients are entitled to expect a good standard of medical care and that this includes "an adequate assessment of the patient's condition, based on the history and clinical signs including, where necessary, an appropriate examination."22 I would suggest that, in this context, such an assessment can only be properly made following a consultation in person, even if a full physical examination is not thought to be necessary to establish whether or not the test results do mean the employee has abused drugs in a particular case. Whilst the personal safety of the medical review 
officer in what may be a contentious situation should not be ignored, this can be addressed by the provision of adequate security arrangements which would, perhaps, be easier to achieve in a workplace medical centre than in a typical general practitioner's surgery. Given the potential conflict of interest between the medical review officer's role, which is to determine whether or not the results of the tests indicate drug abuse, and the occupational health physician's role, which is to determine what advice should be given to the employee and employer in a particular case, in general the same practitioner should not fulfil both roles. Very different skills are required for each of those tasks.

Obviously, if workplace drug testing in urine is considered to be a medical procedure, then the employee subject to such testing has all the rights that are inherent in any medical consultation. In some circumstances, the legislature may consider that the retention of such rights by the person subject to testing is not in the broader public interest. There are some circumstances where the provision of urine samples for drug screening to detect drug use, rather than current intoxication or impairment, has been implied by statute to be an administrative matter rather than a medical matter. For example, prison officers now have the power to require prisoners to provide urine samples or other, non-intimate, body samples to determine whether they have a controlled drug in their body. ${ }^{23}$ In the United States employers are prohibited from administering a medical examination before making an offer of employment to an applicant. However, testing for illicit drugs is not considered to be a medical examination under the relevant Act. ${ }^{24}$ There are clearly very great ethical difficulties for any health care professional involved in the collection, analysis and interpretation of the results obtained in relation to a sample provided under such legislation, particularly where the results are to be shared with a third party without the tested person's explicit consent.

\section{Conclusion}

Workplace screening for drug misuse by urine analysis is now an established part of occupational medical practice in the UK. If the process is to be regarded as being part of medical practice, then the normal ethical constraints of such practice apply. In such circumstances, the practitioners involved must be adequately trained and competent to produce and defend their reports, given the potential consequences for the employee, who is their patient, and to the public, of error. There is no ethical and little, if any, legal justification for any policy which the employer might adopt that attempts to restrict the employee's access to either the analytical reports, the samples he has provided or the medical review officer's notes if he should wish to challenge the medical review officer's opinion or for any other reason. If workplace drug screening is regarded by the employer as a non-medical issue, then the employee should have the same protection that she would be afforded when asked to provide intimate body samples during the course of a criminal investigation. ${ }^{25}$ Such protection may require new legislation.

\section{Acknowledgement}

I am grateful to Dr W S Phillips for her comments on earlier drafts of this paper.

Alexander $R W$ Forrest, LLM, FRCP, FRCPath, CChem, FRSC is Consultant in Clinical Chemistry and Toxicology to the Royal Hallamshire Hospital, Sheffield, w Lecturer in Forensic Toxicology to the University of $\overrightarrow{.}$ Sheffield, Assistant Deputy Coroner for South Yorkshire $\vec{N}$ (West) and Visiting Professor of Toxicology to the 옥 University of Bradford.

\section{References}

1 Bray RM, Marsden ME, Rachal JV, Peterson MR. $\overrightarrow{0}$ Drugs in the military workplace; results of the $1988 \mathrm{~V}$ worldwide survey. In Gust SW et al, eds. Drugs in the workplace: research and evaluation data volume IE Washington DC: NIDA monograph series No 10 1990; 25-44.

2 Ryan J, Zwerling C, Jones $M$. The effectiveness of preemployment drug screening in the prediction of employment outcome. Fournal of Occupational Medicine 1992; 34:1057-1063.

3 Drug Free Workplace. United States of America. Executive Order 12564. Washington DC: 1986 Sept 15.

4 Faculty of Occupational Medicine. Guidelines for testing for drugs of abuse in the workplace. London: Faculty of Occupational Medicine, 1994.

5 Transport and Works Act 1992 , s. $27-1$.

6 Transport and Works Act 1992 , s. $28-3$.

7 Health and Safety at Work etc.Act 1974, s 2.2a and s $7 \mathrm{a}$.

8 Road Traffic Offenders Act 1988, s 155.

9 "Our law recognises no property in a corpse". Erle J. Obiter in Foster $v$ Dodd (1867) LR 3 QB 67,77.

$10 R v$ Rothery [1976] Crim LR 691 and $R v$ Welsh [1974] RTR 478.

11 Nuffield Council on Bioethics. Human tissue: ethical and legal aspects. London: Nuffield Council on Bioethics, 1995.

12 Brahams D. Bailment and donation of parts of the human body. New Law fournal 1989; 139: 803.

13 Holt CJ obiter, 17032 Ld Raynr 909.

14 Road Traffic Offences Act 1988, s $16-1 \mathrm{~b}$ and s 16-7.

15 Access to Health Records Act 1990, s 3.

16 Access to Medical Reports Act 1988, ss 4, 5.

17 General Medical Council. Good medical practice. London: General Medical Council, 1995: para ll.

18 McCurcheon JR, Woods PG. Snack crackers $\sigma$ yield opiate positive urine. Clinical Chemistry 1995; 41: 770-1. 
19 Cone EJ, Welch P, Mitchell JM, Paul BD. Forensic drug testing for opiates: 1. Detection of 6-acetylmorphine in urine as an indicator of recent heroin exposure; drug and assay considerations and detection times. fournal of Analytical Toxicology 1991; 15: 1-7.

20 Cone E, Johnson R, Darwin W, Yousefnejad D, Mell 1, Mitchell J. Passive inhalation of marijuana smoke: urinalysis and room air levels of $\Delta 9$-tetrahydrocannabinol and its metabolites' in human body fluids. Fournal of Analytical Toxicology 1987; 11: 89-96.

21 McLay WDS, ed. Clinical forensic medicine. London: Pinter Publishers Ltd, 1990.

22 See reference 16: para 2.

23 Criminal Justice and Public Order Act 1994, ss 151, 152.

24 Americans with Disabilities Act of 1990, 42 USC $\int 12114$.

25 Police and Criminal Evidence Act 1994, s 62. 